\title{
Episodic and semantic content of memory and imagination: A multilevel analysis
}

\author{
Aleea L. Devitt ${ }^{1}$ • Donna Rose Addis ${ }^{2,3}$ - Daniel L. Schacter ${ }^{1}$
}

Published online: 25 May 2017

(C) Psychonomic Society, Inc. 2017

\begin{abstract}
Autobiographical memories of past events and imaginations of future scenarios comprise both episodic and semantic content. Correlating the amount of "internal" (episodic) and "external" (semantic) details generated when describing autobiographical events can illuminate the relationship between the processes supporting these constructs. Yet previous studies performing such correlations were limited by aggregating data across all events generated by an individual, potentially obscuring the underlying relationship within the events themselves. In the current article, we reanalyzed datasets from eight studies using a multilevel approach, allowing us to explore the relationship between internal and external details within events. We also examined whether this relationship changes with healthy aging. Our reanalyses demonstrated a largely negative relationship between the internal and external details produced when describing autobiographical memories and future imaginations. This negative relationship was stronger and more consistent for older adults and was evident both in direct and indirect measures of semantic content. Moreover, this relationship appears to be specific to episodic tasks, as no relationship was observed for a nonepisodic picture description task. This negative association suggests
\end{abstract}

Electronic supplementary material The online version of this article (doi:10.3758/s13421-017-0716-1) contains supplementary material, which is available to authorized users.

Aleea L. Devitt

aldevitt@gmail.com

1 Department of Psychology, Harvard University, 33 Kirkland Street, Cambridge, MA 02138, USA

2 School of Psychology and Centre for Brain Research, The University of Auckland, Auckland, New Zealand

3 Brain Research New Zealand, Auckland, New Zealand that people do not generate semantic information indiscriminately, but do so in a compensatory manner, to embellish episodically impoverished events. Our reanalysis further lends support for dissociable processes underpinning episodic and semantic information generation when remembering and imagining autobiographical events.

Keywords Aging · Autobiographical memory $\cdot$ Memory · Semantic memory

Autobiographical events - whether memories of personal life occurrences, or simulations of novel future scenarios (Schacter \& Addis, 2007)-are multifaceted in content. Narratives of personal episodes are interwoven with both episodic information (such as sensory details, thoughts and emotions, time and place details) and semantic information (including generalized event knowledge, personal facts devoid of context; Addis, Musicaro, Pan, \& Schacter, 2010; Addis, Wong, \& Schacter, 2008; Levine, Svoboda, Hay, Winocur, \& Moscovitch, 2002). Yet the nature of the relationship between processes supporting the generation of episodic and semantic content when retrieving or simulating personal events is unclear. It has been questioned whether the memory mechanisms underlying the generation of episodic and semantic information are reliant on the same processes or are independent from one another (Greenberg \& Verfaellie, 2010; Manns, Hopkins, \& Squire, 2003; Moscovitch et al., 2005; Squire, 1992; Tulving, 1972). Indeed, while the two are subserved by separate neural systems, some overlaps do exist (Binder, Desai, Graves, \& Conant, 2009; Burianová \& Grady, 2007; Burianová, McIntosh, \& Grady, 2010; Svoboda, McKinnon, \& Levine, 2006).

Correlations between the amount of episodic and semantic information people generate when describing autobiographical 
events (cf. Levine et al., 2002) can provide a means of exploring the relation between the underlying processes. If the mechanisms underpinning episodic and semantic information production are stochastically independent of one another, no correlation between the two types of information would be expected. However, if these constructs rely on similar mechanisms, a positive correlation would be expected between production of episodic and semantic information. For instance, a schematic representation may be necessary to guide episodic simulation, and semantic information may provide a framework that can be populated with episodic information (Atance \& O'Neill, 2001; D'Argembeau \& Mathy, 2011; Irish, Addis, Hodges, \& Piguet, 2012a, 2012b; Irish \& Piguet, 2013). Events that are high in episodic content may require a more extensive underlying semantic framework, and so the production of more episodic information would be accompanied with higher amounts of semantic information.

In contrast, a negative relationship would indicate a dependence between distinct mechanisms underpinning the generation of episodic and semantic content. For instance, semantic information may be provided as compensation when episodic information is sparse (de Vito, Buonocore, Bonnefon, \& Della Sala, 2015; Wang, Yue, \& Huang, 2016), or when an episodic event is not accessed in the first place. In line with this idea, it is theorized that specific episodic autobiographical memories are accessed via personal semantics and generalized autobiographical memories (Conway \& Pleydell-Pearce, 2000). If construction of a memory or imagination is terminated before a specific event is reached, the resulting event should contain more semantic and less episodic information and vice versa for when a specific event is successfully retrieved. Alternatively, a negative relationship may result from a shifting focus between episodic and semantic information, in that retrieving more of one type of information leaves less time or attentional resources for the other type (Cole, Gill, Conway, \& Morrison, 2012).

Four recent studies have addressed this issue by examining the relationship between types of information produced during an autobiographical interview (AI; adapted from Levine et al., 2002). The AI distinguishes between internal details, which correspond to episodic information as defined earlier, and external details, which include semantic information, repetitions, metacognitive statements, and references to events other than the target episode (see below). All four studies found no correlations between internal and external details (Addis et al., 2010; Addis, Sacchetti, Ally, Budson, \& Schacter, 2009; Addis et al., 2008; Cole et al., 2012), suggesting that the generation of episodic information could be unrelated to that of semantic information. ${ }^{1}$ However, these studies were limited in

\footnotetext{
${ }^{1}$ In this paper, we only use the terms internal and external when directly referring to these measures from the AI, otherwise the terms episodic and semantic are used.
}

their use of between-subjects correlations, where the amount of information generated was averaged across all events retrieved or simulated by an individual. As such, it is possible that a negative relationship between internal and external details was obscured by a positive trend in output, where some people tend to generate more information overall, and some people less. Furthermore, individual variation in narrative style could also result in a lack of correlation overall, in that some people might focus more on episodic information, whereas others focus predominately on semantic information (see Addis et al., 2010). As such, a lack of correlation between subjects is by no means conclusive about the underlying relation between these two constructs.

It is also important to emphasize that, as alluded to above, semantic information and the external category used in the AI are not interchangeable concepts. While semantic information typically comprises the majority of external details produced during the AI (see, for instance, Bastin et al., 2013; Levine et al., 2002; Murphy, Troyer, Levine, \& Moscovitch, 2008), other types of information are also captured by the external category, including generalized event descriptions, episodic information irrelevant to the main event, repetitions, and metacognitive thoughts, sometimes in equal measure to semantic details (St-Laurent, Moscovitch, Levine, \& McAndrews, 2009). Cases of semantic dementia exemplify this point; despite difficulty accessing semantic information, the total number of external details produced by patients tends to be similar to or inflated compared with healthy controls, due to the production of higher amounts of off-topic episodic information (Irish et al., 2012a, 2012b). While endeavoring to examine the relationship between internal and semantic details, prior studies used the broader external category, which provides a useful overview_but imperfect measure —of semantic specificity.

Memory retrieval changes associated with healthy aging also provide insight into the relationship between the episodic and semantic content of autobiographical events. Older adults tend to generate fewer internal and more external details on the AI than younger adults when remembering past events (Levine et al., 2002; Piolino, Desgranges, Benali, \& Eustache, 2002; St. Jacques \& Levine, 2007), and simulating novel future and past events (Addis et al., 2010; Addis et al., 2008; Cole, Morrison, \& Conway, 2013; De Beni et al., 2013; Devitt, Tippett, Schacter, \& Addis, 2016; Lapp \& Spaniol, 2017; Rendell et al., 2012; for review, see Schacter, Gaesser, $\&$ Addis, 2013). A number of explanations are viable for this shift in memory content with age.

On the one hand, structural and functional declines in brain regions supporting episodic recall (Buckner, Head, \& Lustig, 2006; Dennis \& Cabeza, 2008; Prull, Gabrieli, \& Bunge, 2000; Raz et al., 2005) may disrupt the ability to generate episodically rich events. Consistent with this idea, older adults activate brain regions supporting episodic construction less 
than younger adults when retrieving autobiographical memories low in episodic richness (Addis, Roberts, \& Schacter, 2011; St. Jacques, Rubin, \& Cabeza, 2012). Moreover, providing retrieval support boosts the generation of internal details for both younger and older adults on the AI (Levine et al., 2002; Madore \& Schacter, 2014). In contrast, regions supporting semantic retrieval are relatively preserved, and semantic memory is relatively unaffected by aging (Allen, Sliwinski, Bowie, \& Madden, 2002; Spaniol, Madden, \& Voss, 2006). Semantic regions are engaged to a greater extent with age during autobiographical memory and imagination (Addis et al., 2011), suggesting that older adults rely on semantic and conceptual information to "flesh out" episodically impoverished events.

Yet on the other hand, older adults exhibit a similar decrease in relevant information and increase in task-irrelevant information production for a picture description task that does not rely on episodic processes, implicating a role of nonepisodic mechanisms in age-related changes in memory and imagination content (Gaesser, Sacchetti, Addis, \& Schacter, 2011). Such mechanisms might include an inability to inhibit irrelevant information (Zacks \& Hasher, 1994), changes in narrative style (Coupland \& Coupland, 1995), or communicative goals that change with age (Adams, Smith, Nyquist, \& Perlmutter, 1997; Carstensen, Isaacowitz, \& Charles, 1999; James, Burke, Austin, \& Hulme, 1998). If older adults spend more of their allocated description time producing semantic information due to these nonepisodic changes, the time available to provide episodic content would be minimized. In both of the above cases, a negative correlation should be evident between episodic and semantic information production. While correlations on AI data reveal no relationship between internal and external details for older adults (Addis et al., 2010; Addis et al., 2009; Addis et al., 2008), it may be that the between-subjects nature of the correlations do not examine the true nature of the underlying relationship between episodic and semantic information.

For between-subjects correlations, each individual contributes only one data point: the average amount of internal relative to external details produced overall. An outcome of this data aggregation across events is that inferences are drawn across different explanatory levels - the individual level and the event level. A between-subjects correlation allows us to question whether individuals who generate high amounts of internal details also generate high or low amounts of external details. However, a more pertinent question is whether, for each individual, events with high amounts of internal details contain more or less external details. The relationship between variables at a higher (individual) level may not reflect - and sometimes might even obscure - the relationship at a lower level. For instance, the Simpson's paradox refers to situations where the patterns of results across explanatory levels is reversed and occurs in psychological research more often than commonly thought (Kievit, Frankenhuis, Waldorp, \& Borsboom, 2013). Thus, in previous AI studies, a negative relationship between the production of internal and external details at the event level may have been obscured by individual-level effects, such as the tendency for some people to produce more details overall, or to selectively focus on the generation of either internal or external information. A more accurate analysis of internal and external detail production would take into account the differing levels on which these effects occur.

Using a multilevel technique overcomes the limitations of previous analyses, by preserving rich trial-by-trial information that is typically lost when aggregating data into participant means, thereby removing the potentially masking effects of data aggregation and allowing exploration of relationships at the event level. Furthermore, in autobiographical memory research, remembered and imagined events are nested within individuals, so events belonging to one person will be more similar to each other than to events belonging to another person. Thus, it has been argued that the most appropriate technique for analyzing such data is multilevel modeling (Wright, 1998; for other examples of using multilevel techniques to explore remembered and imagined events, see D'Argembeau, Renaud, \& Van der Linden, 2011; D'Argembeau \& Van der Linden, 2012; McLelland, Devitt, Schacter, \& Addis, 2015).

\section{The current study}

In the current study, we reexamine the relationship between episodic and semantic information generated during autobiographical event retrieval and imagination using a multilevel approach to analyze AI data. We obtained AI datasets from eight studies (Addis et al., 2010; Addis et al., 2009; Addis et al., 2008; Cole et al., 2013; Devitt et al., 2016; Madore, Gaesser, \& Schacter, 2014, Exp. 1; Martin, 2013, Exp. 4; Roberts \& Addis, 2016), and reanalyzed these data using hierarchical linear modeling (HLM), a statistical approach used to explore data with a nested structure. All studies explored the production of internal and external details when either remembering past events or imagining novel future scenarios. Six studies included healthy older adult participants; five of these studies directly examined differences between younger and older adults in the amount of internal and external details generated during memory retrieval or future imagination. Madore et al. (2014) also examined generation of details in a nonepisodic picture description task as well as the influence of an episodic specificity induction - brief training in recollecting specific details of past experiences - on internal and external detail production. They found that for both younger and older adults, the specificity induction selectively enhanced internal details during descriptions of remembered and imagined events 
while having no influence on external output or performance on the picture description task (see also Madore, Jing, \& Schacter, 2016; Madore \& Schacter, 2014; Schacter \& Madore, 2016).

The studies all used a variant of the AI, in which participants were asked to describe past and future personal episodic events. Despite being asked to retrieve an episodic event in this task, people reliably produce content unrelated to the event in question (i.e., external details, including semantic information), and as such the AI allows for objective assessment of the relative episodic and semantic content of autobiographical events. Our goal was to determine whether the episodic content of autobiographical events predicted the amount of semantic information generated. Given that previous studies examining between-subjects correlations used the broader external category that captured all event-irrelevant information rather than the semantic subcategory (Addis et al., 2010; Addis et al., 2009; Addis et al., 2008; Cole et al., 2012), we first examined the relationship between internal and external details in all eight studies. However, because the external category does not exclusively represent semantic information, we also directly examined the relationship between internal and semantic details in four of the datasets that contained scoring of external subcategories. We hypothesized that a positive relationship would indicate the involvement of a similar mechanism in the generation of episodic and semantic content, while a negative relationship would indicate a dependence between distinct mechanisms underpinning the generation of episodic and semantic content. A lack of correlation could indicate that the mechanisms underpinning episodic and semantic information generation are independent of one another. $^{2}$

We also examined whether the relationship between episodic and semantic content differs between healthy younger and older adults, to inform our understanding of the processes involved in the age-related decline in internal details and increase in external details previously documented during autobiographical event generation on the AI. The inclusion of a nonepisodic picture description task in one dataset further allowed us to differentiate the role of episodic from other nonepisodic mechanisms that could influence the production of event content. If the same relationship is observed between internal and external details in the memory and imagination tasks, and task-relevant and task-irrelevant information in the nonepisodic picture description task, it may suggest that the results for the memory and imagination tasks may be

\footnotetext{
${ }^{2}$ It is possible that even if episodic and semantic information are interdependent, a positive relationship may not be evident. For instance, if semantic scaffolding is needed only up to a certain threshold, above which semantic and episodic information may vary across narratives, then no relationship may be observed. As such, a null correlation may not be definitively indicative of independence between these constructs. We are grateful to an anonymous reviewer for bringing this point to our attention.
}

accounted for (at least in part) by nonepisodic mechanisms such as shifts in attention or inhibition for a negative relationship, or overall information output for a positive relationship. Lastly, given that the episodic specificity induction positively impacts only episodic information, we explored whether this induction altered the relationship between internal and external details.

\section{Method}

\section{Participants}

See Table 1 for participant information for each study. The participants from these studies had no history of neurological or psychiatric impairment. Additional background information is provided in the original papers, and in the Supplementary Information for Roberts and Addis (2016).

\section{Procedure}

All studies used a variant of the AI (see Addis et al., 2008; Levine et al., 2002). In response to either word, memory, or picture cues (see Table 1), participants were given three minutes $^{3}$ to describe in as much detail as possible either a past memory or a future imagination. Each event was required to be temporally and contextually specific, occurring over minutes or hours, but no longer than a day. Future events were to be plausible and novel (not previously experienced by the participant). Participants were instructed to experience all events from a first-person rather than a third-person perspective. For the nonepisodic picture description task in Madore et al. (2014), participants were asked to describe all they could about the picture, including details about the people, objects, and environment depicted.

Participants' event descriptions were audio recorded, and transcripts were segmented into distinct pieces of information, each conveying a unique idea, which were further classified as either internal or external. For remembered or imagined events, internal details referred to episodic information about the event (such as sensory, thought, time, and place information), while external details were those not specific to the event (such as semantic facts, episodic information not pertaining to the main event, generalized events, metacognitive statements, and repetitions). Four of the eight datasets contained scoring of these external subcategories including semantic details (Cole et al., 2013; Devitt et al., 2016; Martin 2013; Roberts \& Addis, 2016). More complete descriptions of the detail subcategories and an example scoring of an AI transcript are available in Table S2 and Fig. S1 in the Supplementary Information. For the picture description task, internal details were those directly depicted in the picture (i.e., task-

\footnotetext{
${ }^{3}$ For Cole et al. (2013) no time limit was imposed.
} 
Table 1 Participant and cue information

\begin{tabular}{|c|c|c|c|c|c|}
\hline \multirow[t]{2}{*}{ Dataset } & \multicolumn{2}{|c|}{ Younger adults } & \multicolumn{2}{|l|}{ Older adults } & \multirow[b]{2}{*}{ Cue type } \\
\hline & Number & Mean age $(S D)$ & Number & Mean age $(S D)$ & \\
\hline Addis et al., 2008 & $16(6$ male $)$ & $25.31(4.66)$ & $16(10$ male $)$ & $72.30(5.00)$ & Words \\
\hline Addis et al., 2009 & - & - & $16(6$ male $)$ & $78.75(5.17)$ & Words \\
\hline Addis et al., 2010 & 17 (9 male) & $21.89(3.61)$ & 18 (7 male) & $74.89(5.56)$ & Memory details \\
\hline Cole et al., 2013 & 32 (8 male) & $24.8(4.4)$ & 28 & $74.64(6.61)$ & Words \\
\hline Devitt et al., 2016 & $20(3 \text { male })^{\mathrm{a}}$ & $20.55(3.63)$ & $20(8 \text { male })^{\mathrm{a}}$ & $71.95(4.77)$ & Memory details \\
\hline Madore et al., 2014 & 24 (11 male) & $19.96(1.61)$ & 24 (14 male) & $76.21(6.86)$ & Pictures \\
\hline Martin, 2013 & 21 (8 male) & Range: $18-35$ & - & - & Memory details \\
\hline Roberts \& Addis, 2016 & 30 (8 male $)$ & $21.2(3.42)$ & - & - & Words \\
\hline
\end{tabular}

a. Subcategory scores were available for only a subset of the participants in the original study

relevant details), while external details were based on inferences (i.e., task-irrelevant details; e.g., describing what the people in the picture could have been talking about).

For half the events in the Madore et al. (2014) dataset the AI was completed following an episodic specificity induction and half following a control induction. In these inductions, participants watched a short film, which they then recalled information about. In the episodic specificity induction, participants were told they were the chief expert about the video, were asked to generate a mental image about the scenes in the video, then were asked to recall information about the surroundings, people, and actions depicted in as much detail as possible. To control for the general requirement to talk about the video, in the control induction participants were asked to report their impressions, thoughts, and feelings about another video. For more detailed instructions regarding each study, we refer the reader to the original papers, and to the Supplementary Information for Roberts and Addis (2016).

\section{Statistical analyses}

Using HLM 7 software (Raudenbush, Bryk, Cheong, Congdon, \& Du Toit, 2011), we created two-level random coefficient models in which each event (memory, imagination, or picture description) was modeled at the within-subjects level and each participant at the between-subjects level (see Table 2 for the number of records at level one and two, and Table 3 for the means for each dataset). Because we were interested in why people produce semantic information in an episodic retrieval task, the level one predictor was number of internal details, and the outcome was number of external details or number of semantic details for analyses on datasets containing subcategory scores. Where relevant, age group (younger or older adults, dummy coded) was included as a level two predictor, along with an age group by internal detail cross-level interaction, allowing us to test whether age influenced the relationship between internal and external/semantic details. To examine whether the specificity induction altered the relationship between internal and external details, we included induction condition (specificity or control, dummy coded), and an internal details by induction condition interaction term as level one predictors in the Madore et al. (2014) models. Note that for all datasets there are fewer cases at level one than what is typically recommended for multilevel modeling (see Maas \& Hox, 2004; Scherbaum \& Ferreter, 2009; Snijders, 2005).

All slopes and intercepts were allowed to vary across participants, accounting for potential between-subjects variability in the relationship between internal and external/semantic details. Models were estimated using a restricted maximum likelihood method, producing unbiased estimates of covariance parameters, with a maximum number of 100 iterations to estimate the parameters (i.e., micro-iterations). Normality of the residuals at levels one and two was acceptable or revealed no influential outliers in all but one case. For analyses examining whether internal details predicted semantic details for the Devitt et al. (2016) dataset, four outliers were detected at level one, where the number of semantic details produced was more than three standard deviations above the mean, or the number of total details produced was truncated. The semantic analyses reported below for Devitt et al. exclude the outlying cases.

\section{Results}

\section{Between-subjects correlations}

In line with the analyses reported in previous studies, we first ran correlations between internal and external details at a between-subjects level, where the amount of details produced was averaged for all events of one type for each individual. We used $\alpha=.002$ to correct for multiple comparisons (Bonferroni-correction, $\alpha=.05 / 22$ correlations). At the between-subjects level, only one correlation exhibited a near 
Table 2 Average number of events per participant, level one and two HLM records, and between-subjects correlations for internal and external details

\begin{tabular}{|c|c|c|c|c|c|}
\hline \multirow[t]{2}{*}{ Event type/dataset } & \multirow[t]{2}{*}{ Events per participant } & \multicolumn{2}{|c|}{ HLM records } & \multicolumn{2}{|c|}{ Between-subjects correlations ( $p$ ) } \\
\hline & & Level 1 & Level 2 & Younger adults & Older adults \\
\hline \multicolumn{6}{|l|}{ Memory } \\
\hline Addis et al., 2008 & 8 & 256 & 32 & $.44(.09)$ & $.19(.48)$ \\
\hline Addis et al., 2009 & 5 & 80 & 16 & - & $-.32(.22)$ \\
\hline Addis et al., 2010 & 4 & 139 & 35 & $.07(.78)$ & $.18(.46)$ \\
\hline Devitt et al., 2016 & 5 & 206 & 40 & $.54(.01)$ & $.31(.18)$ \\
\hline Madore et al., 2014 & 8 & 372 & 48 & $.41(.05)$ & $-.001(.99)$ \\
\hline \multicolumn{6}{|l|}{ Imagination } \\
\hline Addis et al., 2008 & 8 & 256 & 32 & $.19(.48)$ & $.14(.61)$ \\
\hline Addis et al., 2009 & 5 & 80 & 16 & - & $-.52(.04)$ \\
\hline Addis et al., 2010 & 12 & 414 & 35 & $.23(.38)$ & $.05(.85)$ \\
\hline Cole et al., 2013 & $4(\mathrm{YA}), 14(\mathrm{OA})$ & 501 & 60 & $-.51(.003)^{+}$ & $-.10(.63)$ \\
\hline Madore et al., 2014 & 8 & 383 & 48 & $.26(.22)$ & $-.37(.07)$ \\
\hline Martin, 2013 & 12 & 252 & 21 & $-.22(.34)$ & - \\
\hline Roberts \& Addis , 2016 & 8 & 239 & 30 & $.31(.10)$ & - \\
\hline \multicolumn{6}{|l|}{ Picture description } \\
\hline Madore et al., 2014 & 8 & 383 & 48 & $.04(.87)$ & $-.38(.07)$ \\
\hline
\end{tabular}

Note. $\mathrm{YA}=$ younger adults, $\mathrm{OA}=$ older adults. ${ }^{+}$indicates trend at the Bonferroni-corrected $\alpha=.002$

significant negative trend (Cole et al., 2013, younger adults; see Table 2 for statistics). No other correlations were significant at the Bonferroni-corrected threshold. Even at a more liberal threshold of $\alpha=.05$, only two other comparisons were significant, with correlations in opposite directions (positive for Devitt et al., 2016, negative for Addis et al., 2009).

We also ran between-subjects correlations between internal and semantic details for the four datasets containing external subcategory scores using a Bonferroni-corrected $\alpha=.008$ ( $\alpha=.05 / 6$ correlations). Two correlations were significant, one demonstrating a negative relationship (Cole et al., 2013, younger adults, $r=-.56, p=.001$ ), while the other exhibited a positive relationship (Roberts $\&$ Addis, 2016, younger adults, $r=.62, p<.001)$. No other correlations were significant $(r<.26, p>.26)$.

\section{Multilevel analyses: Internal details predicting total external details}

For each dataset and each event type (memory, imagination, and picture description), an initial empty (interceptonly) multilevel model was created, with total external details as the outcome variable. The purpose of these empty models was to test the suitability of HLM for these datasets. All empty models revealed that a significant proportion of the variance in number of external details was due to variation between participants, indicating a multilevel model was appropriate to use (see Table 4).
Next, we investigated whether the number of internal details generated within an event predicted external details, and whether this relationship differed by age group. For each dataset and event type, a two-level model was run with number of external details as the level one outcome, number of internal details as the level one predictor, and where applicable age group (younger and older adults, dummy coded) as a level two predictor, along with an age group by internal detail cross-level interaction. Coefficients and statistics for these models are presented in Table 5. We used $\alpha=.004$ to correct for multiple comparisons (Bonferroni-correction, $\alpha=.05 / 13$ analyses).

For remembered events (see Fig. 1), number of internal details was a negative predictor of external details for three of the five datasets (Addis et al., 2010; Addis et al., 2009; Madore et al., 2014). For one of these datasets (Madore et al., 2014), the effect of internal details was manifested as an age group by internal details (i.e., slope) interaction. Looking at the age groups separately in that dataset, a significant negative relationship was evident for younger adults $(B=-0.05, S E=0.02, t$ ratio $=-3.34$, $d f=23, p=.003)$, with an even stronger negative relationship seen in older adults $(B=-0.19, S E=0.04, t$ ratio $=-5.05, d f=23, p<.001)$.

For imagined events (see Fig. 2), number of internal details was a negative predictor of external details for all seven datasets. For Madore et al. (2014), this effect of internal details was evident as a significant interaction with age group and internal 
Table 3 Descriptive statistics

\begin{tabular}{|c|c|c|c|c|c|c|}
\hline \multirow[t]{2}{*}{ Age group/event type/dataset } & \multicolumn{2}{|l|}{ Internal details } & \multicolumn{2}{|l|}{ External details } & \multicolumn{2}{|c|}{ Semantic details } \\
\hline & Mean $(S D)$ & Range & Mean $(S D)$ & Range & Mean $(S D)$ & Range \\
\hline \multicolumn{7}{|l|}{ Younger adults } \\
\hline \multicolumn{7}{|l|}{ Memory } \\
\hline Addis et al., 2008 & $48.48(13.69)$ & $0-102$ & $17.69(8.06)$ & $0-65$ & - & - \\
\hline Addis et al., 2010 & $61.97(14.00)$ & $7-104$ & $24.31(15.56)$ & $0-85$ & - & - \\
\hline Devitt et al. 2016 & $30.36(13.41)$ & $0-82$ & $8.81(5.03)$ & $0-61$ & $3.33(2.46)$ & $0-14$ \\
\hline Madore et al., 2014 & $95.28(26.36)$ & 26-192 & $5.77(3.71)$ & $0-24$ & - & - \\
\hline \multicolumn{7}{|l|}{ Imagination } \\
\hline Addis et al., 2008 & $41.80(14.14)$ & $2-84$ & $17.09(8.58)$ & $0-52$ & - & - \\
\hline Addis et al., 2010 & $51.25(16.06)$ & $11-103$ & $19.15(10.97)$ & $0-90$ & - & - \\
\hline Cole et al., 2013 & $25.46(7.98)$ & $2-57$ & $11.59(5.76)$ & $0-39$ & $7.96(4.06)$ & $0-36$ \\
\hline Madore et al., 2014 & $91.56(26.50)$ & $29-177$ & $5.69(3.15)$ & $0-29$ & - & - \\
\hline Martin et al., 2013 & $49.59(12.72)$ & $1-103$ & $20.95(12.96)$ & $2-88$ & $8.98(7.19)$ & $0-60$ \\
\hline Roberts \& Addis, 2016 & $39.58(14.71)$ & $2-102$ & $16.43(10.34)$ & $0-65$ & $3.28(2.79)$ & $0-17$ \\
\hline \multicolumn{7}{|l|}{ Picture description } \\
\hline Madore et al., 2014 & $103.56(25.06)$ & $35-198$ & $5.39(3.77)$ & $0-24$ & - & - \\
\hline \multicolumn{7}{|l|}{ Older adults } \\
\hline \multicolumn{7}{|l|}{ Memory } \\
\hline Addis et al., 2008 & $35.32(9.95)$ & $0-83$ & $27.90(12.03)$ & $0-89$ & - & - \\
\hline Addis et al., 2009 & $49.14(12.23)$ & $8-102$ & $39.54(14.17)$ & $4-114$ & - & - \\
\hline Addis et al., 2010 & $44.53(13.47)$ & $13-97$ & $34.94(16.86)$ & $0-101$ & - & - \\
\hline Devitt et al. 2016 & $21.54(8.66)$ & $0-73$ & $21.71(13.15)$ & $0-79$ & $9.79(6.70)$ & $0-39$ \\
\hline Madore et al., 2014 & $60.32(21.04)$ & $3-167$ & $13.08(6.77)$ & $0-51$ & & \\
\hline \multicolumn{7}{|l|}{ Imagination } \\
\hline Addis et al., 2008 & $26.68(8.82)$ & $0-76$ & $27.66(14.03)$ & $0-82$ & - & - \\
\hline Addis et al., 2009 & $35.98(12.45)$ & $0-82$ & $48.11(21.17)$ & $4-120$ & - & - \\
\hline Addis et al., 2010 & $36.02(13.64)$ & $0-91$ & $32.15(11.85)$ & $0-80$ & - & - \\
\hline Cole et al., 2013 & $9.30(5.81)$ & $0-58$ & $17.96(11.62)$ & $0-76$ & $11.32(8.78)$ & $0-57$ \\
\hline Madore et al., 2014 & $55.70(29.86)$ & $1-166$ & $12.69(6.95)$ & $0-45$ & - & - \\
\hline \multicolumn{7}{|l|}{ Picture description } \\
\hline Madore et al., 2014 & $71.37(31.45)$ & $12-179$ & $10.14(7.04)$ & $0-60$ & - & - \\
\hline
\end{tabular}

details (i.e., slope), and the same interaction effect was trending at the Bonferroni-corrected level for Addis et al. (2008). Examining the age groups separately in both datasets revealed a significant negative relationship for younger adults for Addis et al. (2008) ( $B$ $=-0.25, S E=0.06, t$ ratio $=-4.02, d f=15, p=.001)$, but not Madore et al. (2014) $(B=-0.03, S E=0.02, t$ ratio $=-1.79, d f=$ $23, p=.09)$. A significant negative relationship was observed for older adults in both datasets (Addis et al., 2008: $B=-0.54, S E=$ $0.09, t$ ratio $=-6.03, d f=15, p<.001$; Madore et al., 2014: $B=$ $-0.14, S E=0.03, t$ ratio $=-4.76, d f=23, p<.001$ ).

For the nonepisodic picture description task reported in Madore et al. (2014), internal (i.e., task-relevant) details did not predict external (i.e., task-irrelevant) details, and no interaction of internal details by age group was observed (see Fig. 3). Lastly, the internal details by induction condition interaction term was not significant in any of the three models run for the Madore et al. (2014) dataset, suggesting that though the episodic specificity induction had a differential influence on overall internal and external details (see original paper), it did not significantly alter the relationship between these variables.

\section{Multilevel analyses: Internal details predicting semantic details}

Four of the datasets contained scoring of external subcategories, including the amount of semantic details, so for these datasets we ran additional analyses examining whether the number of internal details predicted the 
Table 4 HLM empty model statistics

\begin{tabular}{|c|c|c|c|c|c|c|c|c|c|c|c|c|}
\hline \multirow[t]{2}{*}{ Outcome variable/Dataset } & \multicolumn{4}{|c|}{ Memory } & \multicolumn{4}{|c|}{ Imagination } & \multicolumn{4}{|c|}{ Picture Description } \\
\hline & ICC & $\chi^{2}$ & $d f$ & $p$ & ICC & $\chi^{2}$ & df & $p$ & ICC & $\chi^{2}$ & $d f$ & $p$ \\
\hline \multicolumn{13}{|l|}{ Total external details } \\
\hline Addis et al., 2008 & 0.40 & 193.49 & 31 & $<.001$ & 0.52 & 304.01 & 31 & $<.001$ & - & - & - & - \\
\hline Addis et al., 2009 & 0.20 & 34.20 & 15 & .003 & 0.62 & 136.41 & 15 & $<.001$ & - & - & - & - \\
\hline Addis et al., 2010 & 0.55 & 196.77 & 34 & $<.001$ & 0.47 & 384.45 & 34 & $<.001$ & - & - & - & - \\
\hline Madore et al., 2014 & 0.54 & 469.55 & 47 & $<.001$ & 0.63 & 682.83 & 47 & $<.001$ & 0.68 & 837.26 & 47 & $<.001$ \\
\hline Devitt et al., 2016 & 0.54 & 278.16 & 39 & $<.001$ & - & - & - & - & - & - & - & - \\
\hline Cole et al., 2013 & - & - & - & - & 0.51 & 695.00 & 59 & $<.001$ & - & - & - & - \\
\hline Martin, 2013 & - & - & - & - & 0.65 & 160.96 & 20 & $<.001$ & - & - & - & - \\
\hline Roberts \& Addis, 2016 & - & - & - & - & 0.56 & 321.81 & 29 & $<.001$ & - & - & - & - \\
\hline \multicolumn{13}{|l|}{ Semantic details } \\
\hline Devitt et al., 2016 & 0.53 & 255.18 & 39 & $<.001$ & - & - & - & - & - & - & - & - \\
\hline Cole et al., 2013 & - & - & - & - & 0.45 & 562.91 & 59 & $<.001$ & - & - & - & - \\
\hline Martin, 2013 & - & - & - & - & 0.42 & 192.29 & 20 & $<.001$ & - & - & - & - \\
\hline Roberts \& Addis, 2016 & - & - & - & - & 0.44 & 214.53 & 29 & $<.001$ & - & - & - & - \\
\hline
\end{tabular}

Note. ICC $=$ Intraclass correlation. Bonferroni-corrected $\alpha=.004$

number of semantic details in an event. We first created initial empty (intercept-only) models for each dataset, with semantic details as the outcome variable. All empty models revealed that a significant proportion of the variance in number of external details was attributable to variation between participants, indicating a multilevel model was appropriate to use (see Table 4).

Next, we ran a two-level model with semantic details as the outcome, internal details as the level one predictor, and age group (younger and older adults, dummy coded) as the level two predictor where applicable, along with an age group by internal detail cross-level interaction. Coefficients and statistics for these models are presented in Table 5 . We used $\alpha=.01$ to correct for multiple comparisons (Bonferroni-correction, $\alpha=.05 / 4$ analyses). For three of the four datasets (Cole et al., 2013; Devitt et al., 2016; Martin, 2013), number of internal details was a negative predictor of semantic details for imagined events (see Fig. 4). For Devitt et al. (2016), this effect of internal details was evident as an interaction with age group and internal details (i.e., slope) that was trending at the Bonferroni-corrected level. Examining the age groups separately in this dataset revealed a significant negative relationship of internal and semantic details for older adults $(B=-0.13, S E=0.06, t$ ratio $=-2.14, d f=19, p=$ .046 ) but not younger adults $(B=0.02, S E=0.02, t$ ratio $=0.87$, $d f=19, p=.40)^{4}$

\footnotetext{
4 The Roberts and Addis (2016) dataset had a relatively low proportion of semantic details (19.96\% compared with $37 \%-69 \%$ for the other three semantic datasets; see means in Table 3). To rule out the possibility that floor effects obscured a relationship between episodic and semantic details, we reran the analysis including only those participants with high amounts of semantic details (determined by median split), but no change in results was found.
}

For completion, we also ran analyses examining whether internal details predicted any of the other external subcategories (including, where available, external episodic, routine, repeated and metacognitive details). ${ }^{5}$ Internal details negatively predicted external episodic details for Martin (2013) $(B=-0.08, S E=$ $0.02, t$ ratio $=-3.43, d f=20, p=.003)$ and Roberts and Addis (2016) $(B=-0.26, S E=0.04, t$ ratio $=-6.74, d f=29, p<.001)$, but not Devitt et al. (2016) $(p=.83)$. Internal details positively predicted repeated details for Devitt et al. (2016) $(B=0.03, S E$ $=0.01, t$ ratio $=3.10, d f=38, p=.004)$, but not for the other three datasets $(p>.14)$. Internal details were not predictive of routine or metacognitive details for any of the datasets with subcategory scoring ( $p$ values $>.05$ ).

\section{Discussion}

Previous studies have found no relationship between the amount of internal and external details generated when remembering and imagining autobiographical events on the AI, raising uncertainty over the relation between the underlying mechanisms supporting episodic and semantic constructs (Addis et al., 2010; Addis et al., 2009; Addis et al., 2008; Cole et al., 2012). Yet all prior studies examined this relationship using between-subjects correlations, aggregating data across all events generated by an individual, which could obscure the underlying relationship within the events themselves.

\footnotetext{
${ }^{5}$ The Devitt et al. (2016), Martin (2013), and Roberts and Addis (2016) datasets contained all external subcategories. The Cole et al. (2013) dataset contained semantic details for younger and older adults, and repeated details for younger adults.
} 
Table 5 Unstandardized coefficients and statistics for the HLM analyses predicting number of external/semantic details

\begin{tabular}{|c|c|c|c|c|c|c|c|c|c|c|c|c|c|c|c|c|}
\hline \multirow[t]{2}{*}{ Outcome variable/dataset } & \multirow[t]{2}{*}{ Analysis } & \multicolumn{5}{|c|}{ Memory } & \multicolumn{5}{|c|}{ Imagination } & \multicolumn{5}{|c|}{ Picture Description } \\
\hline & & $B$ & $S E$ & $t$ ratio & $d f$ & $p$ & $B$ & $S E$ & $t$ ratio & $d f$ & $p$ & $B$ & $S E$ & $t$ ratio & $d f$ & $p$ \\
\hline \multicolumn{17}{|l|}{ Total external details } \\
\hline \multirow[t]{2}{*}{ Addis et al., 2008} & Internal details & -0.14 & 0.08 & -1.64 & 30 & .11 & $-0.23 *$ & 0.07 & -3.22 & 30 & .003 & - & - & - & - & - \\
\hline & Age group interaction & -0.13 & 0.12 & -1.11 & 30 & .27 & $-0.31^{+}$ & 0.11 & -2.95 & 30 & .006 & - & - & - & - & - \\
\hline Addis et al., 2009 & Internal details & $-0.61 *$ & 0.11 & -5.33 & 15 & $<.001$ & $-0.63^{*}$ & 0.11 & -5.67 & 15 & $<.001$ & - & - & - & - & - \\
\hline \multirow[t]{2}{*}{ Addis et al., 2010} & Internal details & $-0.52 *$ & 0.10 & -5.18 & 33 & $<.001$ & $-0.37 *$ & 0.08 & -4.75 & 33 & $<.001$ & - & - & - & - & - \\
\hline & Age group interaction & -0.10 & 0.14 & -0.70 & 33 & .49 & -0.24 & 0.11 & -2.28 & 33 & .03 & - & - & - & - & - \\
\hline \multirow[t]{3}{*}{ Madore et al., 2014} & Internal details & -0.05 & 0.02 & -2.12 & 46 & .04 & -0.03 & 0.02 & -1.58 & 46 & .12 & -0.02 & 0.02 & -0.88 & 46 & .38 \\
\hline & Age group interaction & $-0.12 *$ & 0.03 & -3.32 & 46 & .002 & $-0.10 *$ & 0.03 & -3.09 & 46 & .003 & -0.07 & 0.04 & -1.93 & 46 & .06 \\
\hline & Induction interaction & -0.02 & 0.03 & -0.61 & 46 & .55 & -0.02 & 0.02 & -0.67 & 46 & .51 & -0.02 & 0.02 & -0.78 & 46 & .44 \\
\hline \multirow[t]{2}{*}{ Devitt et al., 2016} & Internal details & -0.10 & 0.10 & -0.97 & 38 & .34 & - & - & - & - & - & & & & & \\
\hline & Age group interaction & -0.17 & 0.15 & -1.13 & 38 & .26 & - & - & - & - & - & & & & & \\
\hline \multirow[t]{2}{*}{ Cole et al., 2013} & Internal details & - & - & - & - & - & $-0.49 *$ & 0.10 & -4.98 & 58 & $<.001$ & & & & & \\
\hline & Age group interaction & - & - & - & - & - & 0.25 & 0.13 & 1.92 & 58 & .06 & & & & & \\
\hline Martin, 2013 & Internal details & - & - & - & - & - & $-0.32 *$ & 0.05 & -6.13 & 20 & $<.001$ & & & & & \\
\hline Roberts \& Addis, 2016 & Internal details & - & - & - & - & - & $-0.36^{*}$ & 0.05 & -7.16 & 29 & $<.001$ & & & & & \\
\hline \multicolumn{17}{|l|}{ Semantic details } \\
\hline \multirow[t]{2}{*}{ Devitt et al., 2016} & Internal details & 0.02 & 0.04 & 0.38 & 38 & .71 & - & - & - & - & - & - & - & - & - & - \\
\hline & Age group interaction & $-0.14^{+}$ & 0.06 & -2.27 & 38 & .03 & - & - & - & - & - & - & - & - & - & - \\
\hline \multirow[t]{2}{*}{ Cole et al., 2013} & Internal details & - & - & - & - & - & $-0.36^{*}$ & 0.08 & -4.54 & 58 & $<.001$ & - & - & - & - & - \\
\hline & Age group interaction & - & - & - & - & - & 0.17 & 0.10 & 1.64 & 58 & .11 & - & - & - & - & - \\
\hline Martin, 2013 & Internal details & - & - & - & - & - & $-0.19 *$ & 0.06 & -3.26 & 20 & .004 & - & - & - & - & - \\
\hline Roberts \& Addis, 2016 & Internal details & - & - & - & - & - & -0.00 & 0.02 & -0.09 & 29 & .93 & - & - & - & - & - \\
\hline
\end{tabular}

Note. For models with total external details as the outcome variable, Bonferroni-corrected $\alpha=.004$. For models with semantic details as the outcome variable, Bonferroni-corrected $\alpha=.01 . *$ indicates significance at the relevant Bonferroni-corrected $\alpha .{ }^{+}$indicates trend at the relevant Bonferronicorrected $\alpha$

Furthermore, previous studies measured semantic information indirectly, through an overall measure of "external" details, a broad category that also encompasses repetitions of episodic content, episodic information irrelevant to the main event, and metacognitive thoughts. In the current study, we reanalyzed data from eight AI studies using a multilevel modeling approach, which allowed us to explore the relationship between internal and external details for events within subjects while taking into account the nested nature of the data. Our aim was to determine whether the internal details produced when describing autobiographical events could predict the amount of external details generated. Four of the studies also contained direct measures of semantic details, allowing us to more directly examine the relationship between internal and semantic detail production. We further examined whether the relationship between the production of internal and external/semantic details changed with healthy aging, for a non-episodic picture description task, and with a specificity induction that selectively increases internal details.

Our reanalyses demonstrated an overall negative relationship between the number of internal and external details generated within autobiographical events. This relationship was evident for three of the five studies examining memories, and for all seven studies examining future imagination. Crucially, no relationship was found for a nonepisodic picture description task, suggesting that the negative relationship between internal and external details is specific to tasks with an episodic component. These negative associations demonstrate that people do not generate external details indiscriminately when describing autobiographical events but are more likely to do so when internal details are low. Furthermore, three of the four datasets containing finer grained scoring of external subcategories demonstrated a negative relationship between internal and semantic details (albeit this was only trending for one of the datasets), while a negative association for internal details was less consistently observed with external episodic details, and not at all with other external subcategories. Thus, importantly, the negative relationship between internal and semantic details mirror the results with the total external category and support the notion that the memory processes supporting episodic and semantic information generation are reliant on distinct yet dependent mechanisms. 

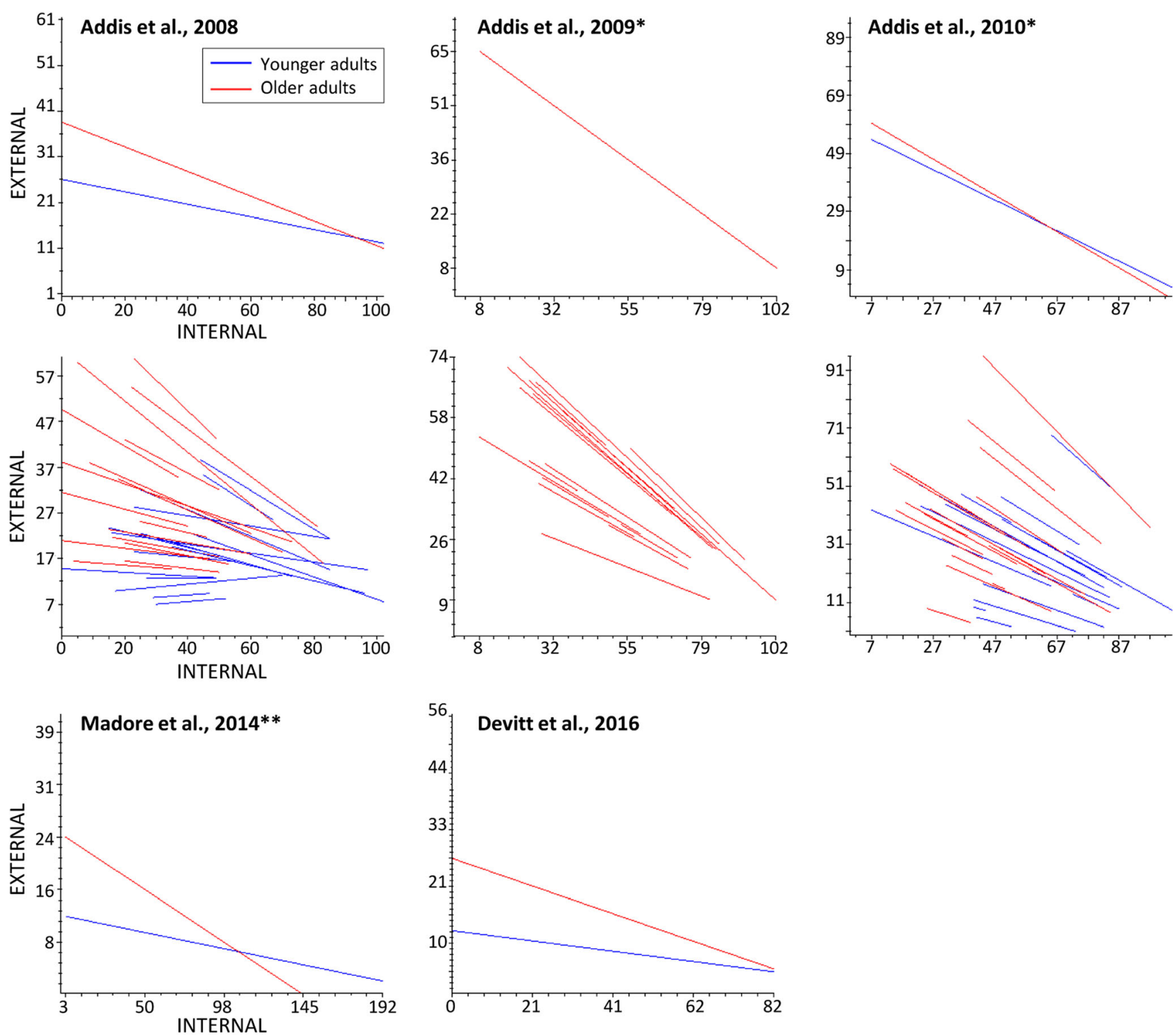

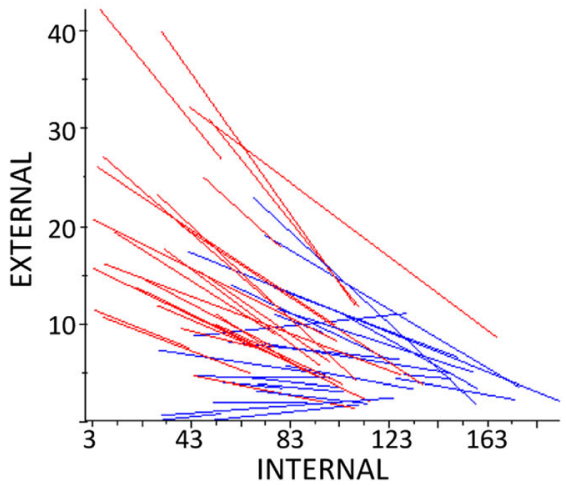

Fig. 1 Regression lines for the relationship between number of internal and external details generated when describing memories in the autobiographical interview. Overall group regression lines are above,

The negative relationship between internal and external/ semantic details may reflect the compensatory generation of semantic information when episodic content is low. In support of

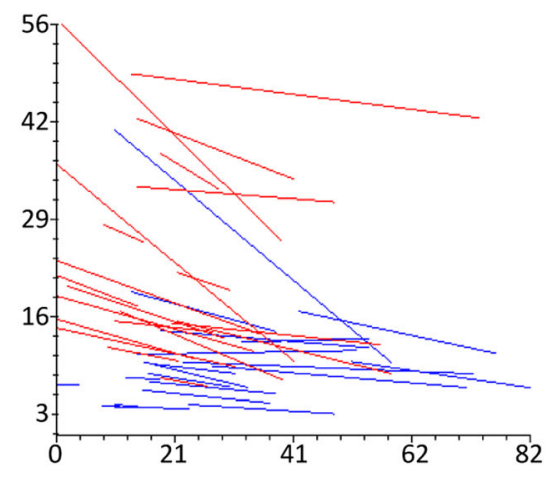

and individual participant regression lines below. Blue line $=$ younger adults, red line $=$ older adults. $*$ main effect of internal details $p<.004$; ** age group by internal details interaction $p<.004$. (Color figure online)

this interpretation, disrupting spatial imagery in younger adults decreases the number of internal details produced during future imagination, which is accompanied by an increase in external 

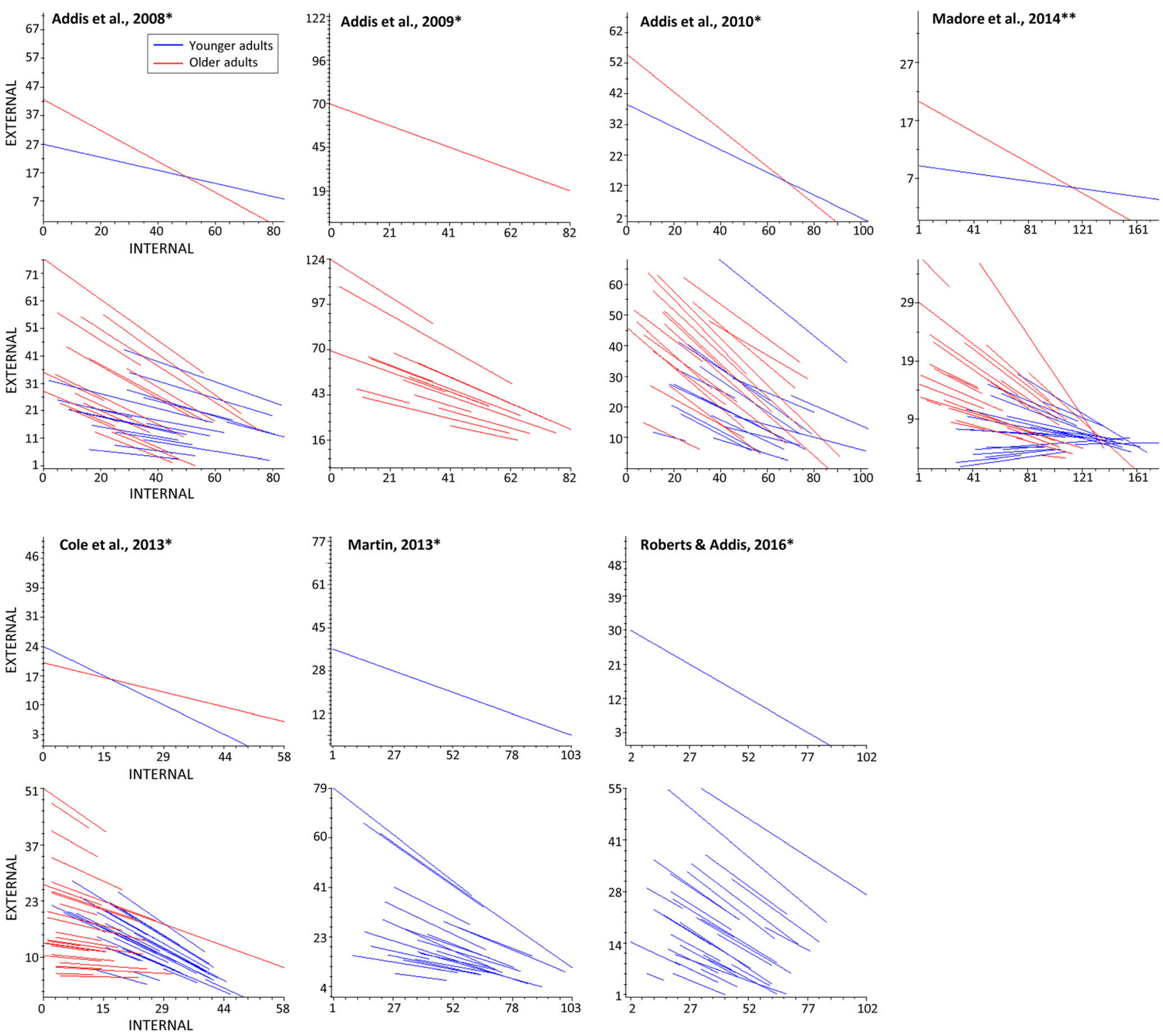

Fig. 2 Regression lines for the relationship between number of internal and external details generated when describing imagined future events in the autobiographical interview. Overall group regression lines are above,

details (De Vito et al., 2015). Semantic memory contributes more when constructing a novel compared to a familiar future scenario, likely because fewer related episodic elements are available to construct novel events (Wang et al., 2016). Likewise, if a specific event is unable to be accessed, the search process often terminates at a higher level of event abstraction, and the resulting event could therefore be more likely to contain semantic or generalized information (Conway \& Pleydell-Pearce, 2000; Ford, Rubin, \& Giovanello, 2014).

Alternatively, the negative relationship between internal and external/semantic details may be the result of a greater focus on irrelevant information, leaving less time or attentional resources available for retrieving episodic details. However, the lack of association in the picture description task speaks against this

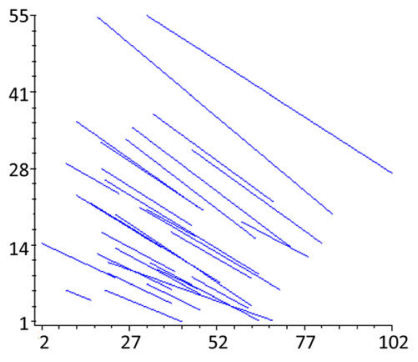

and individual participant regression lines below. Blue line $=$ younger adults, red line $=$ older adults. $*$ main effect of internal details $p<.004$; $* *$ age group by internal details interaction $p<.004$. (Color figure online)

possibility: If people are distracted by task-irrelevant information, then a negative trend was expected between internal (taskrelevant) and external (task-irrelevant) details irrespective of the episodic/nonepisodic nature of the task. Relevant to this point, Zavagnin, De Beni, Borella, and Carretti (2016) found that for future imaginations, reduced inhibition ability was associated with a greater production of external details with age but not with a lowered production of internal details, further suggesting that inhibition alone does not account for the pattern of increased external and decreased internal details at the event level. Moreover, Zavagnin et al. (2016) found no association between inhibition and external details for remembered events, potentially implicating different mechanisms in the production of irrelevant content for memory retrieval and novel event simulation. 

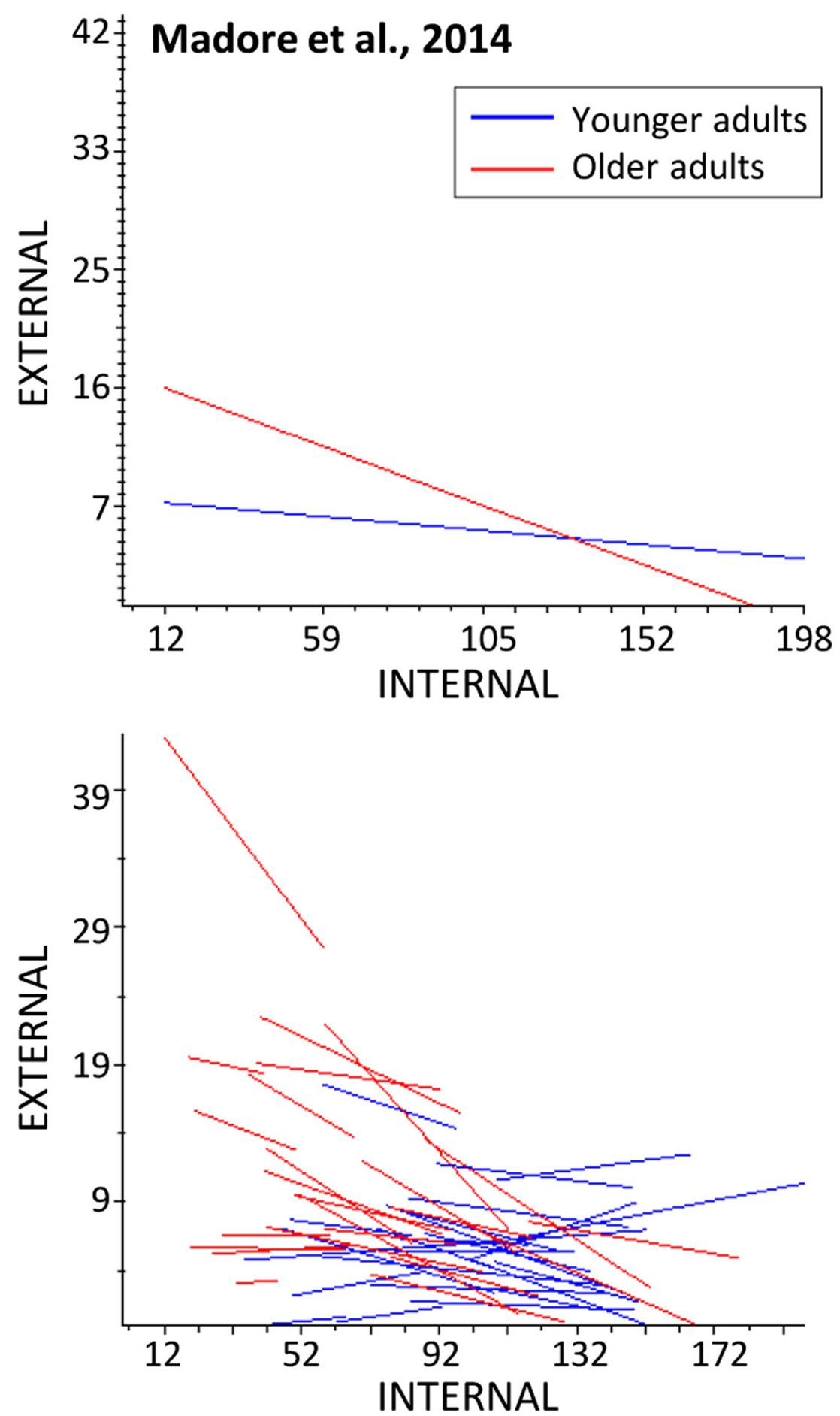

Fig. 3 Regression lines for the relationship between number of internal and external details generated when describing pictures in the autobiographical interview. Overall group regression lines are above,

Patient studies lend support for the view that semantic information can compensate for low episodic content. While generally patients with episodic amnesia attributable to damage to the hippocampus and related structures are impaired at both remembering past events and imagining personal future episodes (Andelman, Hoofien, Goldberg, Aizenstein, \& Neufeld, and individual participant regression lines below. Blue line = younger adults, red line $=$ older adults. (Color figure online)

2010; Cole, Morrison, Barak, Pauly-Takacs, \& Conway, 2016; Hassabis, Kumaran, Vann, \& Maguire, 2007; Klein, Loftus, \& Kihlstrom, 2002; Kurczek et al., 2015; Kwan, Carson, Addis, \& Rosenbaum, 2010; Race, Keane, \& Verfaellie, 2011), a subset of such patients - particularly those with developmental amnesia-retain some ability to simulate future events 

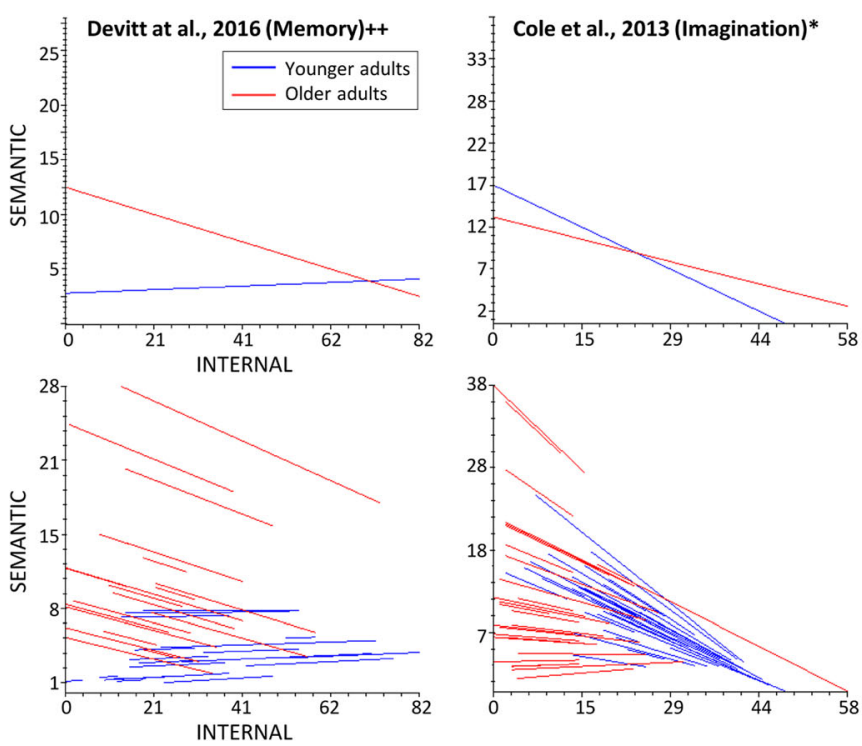

Fig. 4 Regression lines for the relationship between number of internal and semantic details generated when describing memories and future imaginations in the autobiographical interview. Overall group regression lines are above, and individual participant regression lines

(Cooper, Vargha-Khadem, Gadian, \& Maguire, 2011; Dede, Wixted, Hopkins, \& Squire, 2016; Hurley, Maguire, \& Vargha-Khadem, 2011; Maguire, Vargha-Khadem, \& Hassabis, 2010; Squire et al., 2010). However, when such patients generate internal details during future imagination, descriptions of these events seem to be fragmented and lacking in spatial coherence (Hassabis et al., 2007; though see Dede et al., 2016). It is speculated that these patients are drawing from preserved semantic or generalized memory to outline episodic-like future thoughts (Hurley et al., 2011; Maguire \& Hassabis, 2011; Race et al., 2011). Differences in the location and extent of medial temporal and cortical damage likely account for why this compensatory strategy is not employed by all patients with episodic amnesia. It is also important to consider that the relationship between episodic and semantic processes in developmental amnesia may not be applicable to that of healthy individuals or other amnesic patients, given the early onset of injury and potential for alternative compensatory neural activity and cognitive strategies. Future studies should attempt to determine whether the relationship between internal and external/semantic details within events differs across clinical populations. For instance, patients with Alzheimer's disease and semantic dementia have difficulty generating internal and external details when remembering and imagining autobiographical events (Addis et al., 2009; Irish \& Piguet, 2013). If semantic memory is unavailable to compensate for sparse episodic information, such patients should exhibit no relationship between the number of internal and external details generated during autobiographical retrieval and simulation.

While both younger and older adults displayed the negative relationship between internal and external/semantic details, this
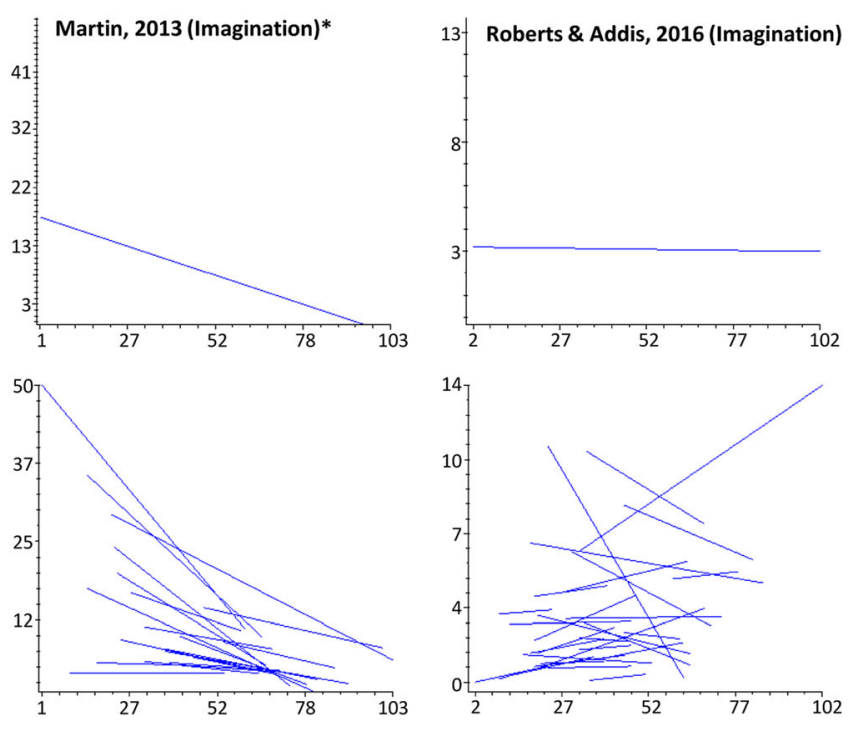

below. Blue line $=$ younger adults, red line $=$ older adults. $*$ main effect of internal details $p<.01 ; * *$ age group by internal details interaction $p<$ $.01 ;^{++}$age group by internal details interaction $p<.05$. (Color figure online)

relationship appeared to be stronger and more consistent for older adults, as indicated by a significant age group by internal details interaction for three of the total external detail analyses, and one of the semantic detail analyses. The lack of association in the nonepisodic picture description tasks implicates a role of episodic mechanisms in the negative relationship between internal and external/semantic details, yet processes that are not specifically memory-related might also contribute to this relationship. For instance, changes in narrative style and communicative goals with age (Adams et al., 1997; Carstensen et al., 1999; Coupland \& Coupland, 1995; James et al., 1998), or salient concerns about age-related memory deterioration (Anderson et al., 2008; Hoyer \& Verhaeghen, 2006) may mean older adults preferentially adopt the strategy of using semantic information as a means of compensating for reductions in overall recollective abilities. In contrast, younger adults may not as readily recruit semantic information to embellish episodically impoverished events. In line with this view, neuroimaging evidence demonstrates that subjective details ratings are correlated with activation in areas involved in episodic imagery for younger adults, but for areas involved in conceptual information for older adults (Addis et al., 2011).

It might be asked to what extent this negative relationship reflects a trade-off between internal and external details. A number of lines of evidence run counter to the idea of a total trade-off. The episodic specificity induction did not alter the overall relationship between internal and external details, meaning that if the generation of external details is entirely a secondary by-product of the amount of internal details (or vice versa), a reciprocal effect between the two should be observed. However, it has previously been shown that in most 
experiments the episodic specificity induction increases internal details but does not decrease external details (Madore et al., 2014; Madore, Jing, et al., 2016; Madore \& Schacter, 2014, 2016; Madore, Szpunar, Addis, \& Schacter, 2016; but see Jing, Madore, \& Schacter, 2016; Madore, Addis, \& Schacter, 2015). Furthermore, different types of future imaginations can alter the amount of internal details generated, with no concurrent effects on external details (de Vito, Neroni, Gamboz, Della Sala, \& Brandimonte, 2015; see also Neroni, Gamboz, De Vito, \& Brandimonte, 2016), and age-related decreases in internal details have been reported even when the number of external details does not differ with age (Madore \& Schacter, 2014; Zavagnin et al., 2016). Future research would benefit from considering the nature of the dependence of the episodic and semantic processes involved in autobiographical event retrieval and simulation.

There are limitations to using the Levine et al. (2002) interview and coding procedure to measure the contribution of memory systems supporting the production of episodic and semantic information when remembering and imagining personal episodes. For instance, participants are asked to generate specific events, which may bias them away from retrieval of semantic details (note however, that within the AI scheme, participants are not restricted in the type of details they produce, only in the specificity of the event as a whole). It would be worthwhile to explore the interplay between internal and external details in a setting where event specificity is not restricted. Moreover, it has been argued that analysis of the content of event descriptions may not accurately reflect the underlying contributions of episodic and semantic memory systems (see Klein, 2015). Others have suggested that episodic and semantic memory might be better conceptualized as a continuum, rather than two discrete categories, particularly given that semantic memory can sometimes contribute to the production of internal details, and episodic memory may sometimes be involved in the generation of external details (Greenberg \& Verfaellie, 2010). Lastly, one of the datasets (Roberts \& Addis, 2016) exhibited a relationship between internal and external details that was not evident between internal and semantic details. Moreover, semantic details were not the only external subcategory to exhibit a negative relationship with internal details; two datasets also displayed an internal by external episodic details association. While total external details are useful as a heuristic overview of semantic details, and oftentimes semantic details are the predominant subcategory of external details generated by healthy individuals, these discrepancies highlight the fact that the two are not completely interchangeable, and caution is advised in generalizing results from total external details to underlying semantic mechanisms. It also highlights the need to use finer grained scoring of external (and internal) detail subcategories in order to draw more specific conclusions from data. Nevertheless, the AI is one of the most commonly used tools in the memory and imagination literature, allowing empirical study of personal and multifaceted autobiographical experiences, and offering insights into the nature of event construction and mental time travel.

In summary, our reanalyses demonstrated a largely, though not invariably, negative relationship between the amount of internal and external details produced when describing autobiographical memories and future imaginations, across eight datasets. This relationship appears to be specific to tasks with an episodic component, as no relationship between internal and external details was observed for a nonepisodic picture description task. This negative association demonstrates that people do not generate task-irrelevant information indiscriminately, but likely to do so as a means of embellishing episodically impoverished events. Older adults in particular may use this strategy to compensate for age-related declines in recollective ability. A negative relationship was also found directly between internal and semantic details for three of the four datasets for which this information was available, lending greater support for dissociable memory processes underlying episodic and semantic information generation. More broadly, because this negative relationship was not evident in the original analyses using conventional between-subjects correlations, these reanalyses demonstrate the value of taking into account the inherently nested structure of autobiographical events (Wright, 1998). Relations among variables can differ at varying hierarchical levels, thus it is important to consider that mechanisms operating on the individual level can be differentiated from those operating at the event level. Multilevel techniques are one way to reveal relationships between variables that might be obscured by data aggregation.

Acknowledgements We thank Scott Cole, Martin Conway, Kevin Madore, Victoria McClelland, Catriona Morrison and Reece Roberts for kindly supplying datasets for our reanalyses. This work was supported by a National Institute on Aging [Grant No. R01 AG08441] awarded to D.L.S. as well as a Marsden grant [12-UOA-254] and a Rutherford Discovery Fellowship [RDF-10-UOA-024] awarded to D.R.A.

\section{References}

Adams, C., Smith, M. C., Nyquist, L., \& Perlmutter, M. (1997). Adult age-group differences in recall for the literal and interpretive meanings of narrative text. The Journals of Gerontology Series B: Psychological Sciences and Social Sciences, 52B(4), 187-195.

Addis, D. R., Musicaro, R., Pan, L., \& Schacter, D. L. (2010). Episodic simulation of past and future events in older adults: Evidence from an experimental recombination task. Psychology and Aging, 25(2), 369-376.

Addis, D. R., Roberts, R. P., \& Schacter, D. L. (2011). Age-related neural changes in autobiographical remembering and imagining. Neuropsychologia, 49(13), 3656-3669.

Addis, D. R., Sacchetti, D. C., Ally, B. A., Budson, A. E., \& Schacter, D. L. (2009). Episodic simulation of future events is impaired in mild Alzheimer's disease. Neuropsychologia, 47(12), 2660-2671.

Addis, D. R., Wong, A. T., \& Schacter, D. L. (2008). Age-related changes in the episodic simulation of future events. Psychological Science, 19, 33-41. 
Allen, P. A., Sliwinski, M., Bowie, T., \& Madden, D. J. (2002). Differential age effects in semantic and episodic memory. The Journals of Gerontology Series B: Psychological Sciences and Social Sciences, 57(2), 173-186.

Andelman, F., Hoofien, D., Goldberg, I., Aizenstein, O., \& Neufeld, M. Y. (2010). Bilateral hippocampal lesion and a selective impairment of the ability for mental time travel. Neurocase, 16(5), 426-435.

Anderson, N. D., Ebert, P. L., Jennings, J. M., Grady, C. L., Cabeza, R., \& Graham, S. J. (2008). Recollection- and familiarity-based memory in healthy aging and amnestic mild cognitive impairment. Neuropsychology, 22(2), 177-187.

Atance, C. M., \& O’Neill, D. K. (2001). Episodic future thinking. Trends in Cognitive Sciences, 5(12), 533-539.

Bastin, C., Feyers, D., Jedidi, H., Bahri, M. A., Degueldre, C., Lemaire, C., . . . Salmon, E. (2013). Episodic autobiographical memory in amnestic mild cognitive impairment: What are the neural correlates? Human Brain Mapping, 34(8), 1811-1825.

Binder, J. R., Desai, R. H., Graves, W. W., \& Conant, L. L. (2009). Where is the semantic system? A critical review and meta-analysis of 120 functional neuroimaging studies. Cerebral Cortex, 19(12), 2767-2796.

Buckner, R. L., Head, D., \& Lustig, C. (2006). Brain changes in aging: A lifespan perspective. In E. Bialystok \& F. I. M. Craik (Eds.), Lifespan cognition: Mechanisms of change (pp. 27-42). New York: Oxford University Press.

Burianová, H., \& Grady, C. L. (2007). Common and unique neural activations in autobiographical, episodic, and semantic retrieval. Journal of Cognitive Neuroscience, 19(9), 1520-1534.

Burianová, H., McIntosh, A. R., \& Grady, C. L. (2010). A common functional brain network for autobiographical, episodic, and semantic memory retrieval. NeuroImage, 49(1), 865-874.

Carstensen, L. L., Isaacowitz, D. M., \& Charles, S. T. (1999). Taking time seriously: A theory of socioemotional selectivity. American Psychologist, 54(3), 165-181.

Cole, S. N., Gill, N. C. L., Conway, M. A., \& Morrison, C. M. (2012). Mental time travel: Effects of trial duration on episodic and semantic content. The Quarterly Journal of Experimental Psychology, 65(12), 2288-2296.

Cole, S. N., Morrison, C. M., Barak, O., Pauly-Takacs, K., \& Conway, M. A. (2016). Amnesia and future thinking: Exploring the role of memory in the quantity and quality of episodic future thoughts. British Journal of Clinical Psychology, 55(2), 206-224.

Cole, S. N., Morrison, C. M., \& Conway, M. A. (2013). Episodic future thinking: Linking neuropsychological performance with episodic detail in young and old adults. The Quarterly Journal of Experimental Psychology, 66(9), 1687-1706.

Conway, M. A., \& Pleydell-Pearce, C. W. (2000). The construction of autobiographical memories in the self-memory system. Psychological Review, 107(2), 261-288.

Cooper, J. M., Vargha-Khadem, F., Gadian, D. G., \& Maguire, E. A. (2011). The effect of hippocampal damage in children on recalling the past and imagining new experiences. Neuropsychologia, 49(7), $1843-1850$

Coupland, N., \& Coupland, J. (1995). Discourse, identity, and aging. In J. F. Nussbaum \& J. Coupland (Eds.), Handbook of communication and aging research (pp. 79-103). Hillsdale: Erlbaum.

D'Argembeau, A., \& Mathy, A. (2011). Tracking the construction of episodic future thoughts. Journal of Experimental Psychology: General, 140(2), 258-271.

D'Argembeau, A., Renaud, O., \& Van der Linden, M. (2011). Frequency, characteristics and functions of future-oriented thoughts in daily life. Applied Cognitive Psychology, 25(1), 96-103.

D'Argembeau, A., \& Van der Linden, M. (2012). Predicting the phenomenology of episodic future thoughts. Consciousness and Cognition, 21(3), 1198-1206.

De Beni, R., Borella, E., Carretti, B., Zavagnin, M., Lazzarini, L., \& Milojevi, G. (2013). Remembering the past and imagining the future: Age-related differences between young, young-old and oldold. Aging Clinical and Experimental Research, 25(1), 89-97.

de Vito, S., Buonocore, A., Bonnefon, J.-F., \& Della Sala, S. (2015). Eye movements disrupt episodic future thinking. Memory, 23(6), 796805.

de Vito, S., Neroni, M. A., Gamboz, N., Della Sala, S., \& Brandimonte, M. A. (2015). Desirable and undesirable future thoughts call for different scene construction processes. The Quarterly Journal of Experimental Psychology, 68(1), 75-82.

Dede, A. J. O., Wixted, J. T., Hopkins, R. O., \& Squire, L. R. (2016). Autobiographical memory, future imagining, and the medial temporal lobe. Proceedings of the National Academy of Sciences, 113(47), 13474-13479.

Dennis, N. A., \& Cabeza, R. (2008). Neuroimaging of healthy cognitive aging. In F. I. M. Craik \& T. A. Salthouse (Eds.), The handbook of aging and cognition (3rd ed., pp. 1-54). New York: Psychology Press.

Devitt, A. L., Tippett, L. J., Schacter, D. L., \& Addis, D. R. (2016). Autobiographical memory conjunction errors in younger and older adults: Evidence for a role of inhibitory ability. Psychology and Aging, 31(8), 927-942.

Ford, J. H., Rubin, D. C., \& Giovanello, K. S. (2014). Effects of task instruction on autobiographical memory specificity in young and older adults. Memory, 22(6), 722-736.

Gaesser, B., Sacchetti, D. C., Addis, D. R., \& Schacter, D. L. (2011). Characterizing age-related changes in remembering the past and imagining the future. Psychology and Aging, 26, 80-84.

Greenberg, D. L., \& Verfaellie, M. (2010). Interdependence of episodic and semantic memory: Evidence from neuropsychology. Journal of the International Neuropsychological Society, 16(5), 748-753.

Hassabis, D., Kumaran, D., Vann, S. D., \& Maguire, E. A. (2007). Patients with hippocampal amnesia cannot imagine new experiences. Proceedings of the National Academy of Sciences, 104, 1726-1731.

Hoyer, W. J., \& Verhaeghen, P. (2006). Memory aging. In J. Birren \& W. Schaie (Eds.), Handbook of the psychology of aging (Vol. 6, pp. 209-232). Burlington: Elsevier Academic Press.

Hurley, N. C., Maguire, E. A., \& Vargha-Khadem, F. (2011). Patient HC with developmental amnesia can construct future scenarios. Neuropsychologia, 49(13), 3620-3628.

Irish, M., Addis, D. R., Hodges, J. R., \& Piguet, O. (2012a). Considering the role of semantic memory in episodic future thinking: Evidence from semantic dementia. Brain, 135(7), 2178-2191.

Irish, M., Addis, D. R., Hodges, J. R., \& Piguet, O. (2012b). Exploring the content and quality of episodic future simulations in semantic dementia. Neuropsychologia, 50(14), 3488-3495.

Irish, M., \& Piguet, O. (2013). The pivotal role of semantic memory in remembering the past and imagining the future. Frontiers in Behavioral Neuroscience, 7, 27.

James, L. E., Burke, D. M., Austin, A., \& Hulme, E. (1998). Production and perception of "verbosity" in younger and older adults. Psychology and Aging, 13(3), 355-367.

Jing, H. G., Madore, K. P., \& Schacter, D. L. (2016). Worrying about the future: An episodic specificity induction impacts problem solving, reappraisal, and well-being. Journal of Experimental Psychology: General, 145(4), 402-418.

Kievit, R. A., Frankenhuis, W. E., Waldorp, L. J., \& Borsboom, D. (2013). Simpson's paradox in psychological science: A practical guide. Frontiers in Psychology, 4, 513.

Klein, S. B. (2015). What memory is. Wiley Interdisciplinary Reviews: Cognitive Science, 6(1), 1-38.

Klein, S. B., Loftus, J., \& Kihlstrom, J. F. (2002). Memory and temporal experience: the effects of episodic memory loss on an amnesic patient's ability to remember the past and imagine the future. Social Cognition, 20(5), 353-379.

Kurczek, J., Wechsler, E., Ahuja, S., Jensen, U., Cohen, N. J., Tranel, D., \& Duff, M. (2015). Differential contributions of hippocampus and 
medial prefrontal cortex to self-projection and self-referential processing. Neuropsychologia, 73, 116-126.

Kwan, D., Carson, N., Addis, D. R., \& Rosenbaum, R. S. (2010). Deficits in past remembering extend to future imagining in a case of developmental amnesia. Neuropsychologia, 48(11), 3179-3186.

Lapp, L. K., \& Spaniol, J. (2017). Impact of age-relevant goals on future thinking in younger and older adults. Memory, 1-14. doi:10.1080/ 09658211.2017.1284240

Levine, B., Svoboda, E., Hay, J., Winocur, G., \& Moscovitch, M. (2002). Aging and autobiographical memory: Dissociating episodic from semantic retrieval. Psychology and Aging, 17, 677-689.

Maas, C. J. M., \& Hox, J. J. (2004). The influence of violations of assumptions on multilevel parameter estimates and their standard errors. Computational Statistics \& Data Analysis, 46(3), 427-440.

Madore, K. P., Addis, D. R., \& Schacter, D. L. (2015). Creativity and memory: Effects of an episodic-specificity induction on divergent thinking. Psychological Science, 26, 1461-1468.

Madore, K. P., Gaesser, B., \& Schacter, D. L. (2014). Constructive episodic simulation: Dissociable effects of a specificity induction on remembering, imagining, and describing in young and older adults. Journal of Experimental Psychology: Learning, Memory, and Cognition, 40(3), 609-622.

Madore, K. P., Jing, H. G., \& Schacter, D. L. (2016). Divergent creative thinking in young and older adults: Extending the effects of an episodic specificity induction. Memory \& Cognition, 44(6), 974-988.

Madore, K. P., \& Schacter, D. L. (2014). An episodic specificity induction enhances means-end problem solving in young and older adults. Psychology and Aging, 29(4), 913-924.

Madore, K. P., \& Schacter, D. L. (2016). Remembering the past and imagining the future: Selective effects of an episodic specificity induction on detail generation. The Quarterly Journal of Experimental Psychology, 69(2), 285-298.

Madore, K. P., Szpunar, K. K., Addis, D. R., \& Schacter, D. L. (2016). Episodic specificity induction impacts activity in a core brain network during construction of imagined future experiences. Proceedings of the National Academy of Sciences, 113(38), 10696-10701.

Maguire, E. A., \& Hassabis, D. (2011). Role of the hippocampus in imagination and future thinking. Proceedings of the National Academy of Sciences, 108(11), E39-E39.

Maguire, E. A., Vargha-Khadem, F., \& Hassabis, D. (2010). Imagining fictitious and future experiences: Evidence from developmental amnesia. Neuropsychologia, 48(11), 3187-3192.

Manns, J. R., Hopkins, R. O., \& Squire, L. R. (2003). Semantic memory and the human hippocampus. Neuron, 38(1), 127-133.

Martin, V. C. (2013). Memory for the future: The encoding and phenomenology of episodic simulations (Unpublished doctoral thesis). The University of Auckland, Auckland, New Zealand.

McLelland, V. C., Devitt, A. L., Schacter, D. L., \& Addis, D. R. (2015). Making the future memorable: The phenomenology of remembered future events. Memory, 23(8), 1255-1263.

Moscovitch, M., Rosenbaum, R. S., Gilboa, A., Addis, D. R., Westmacott, R., Grady, C. L., . . Nadel, L. (2005). Functional neuroanatomy of remote episodic, semantic and spatial memory: A unified account based on multiple trace theory. Journal of Anatomy, 207(1), 35-66.

Murphy, K. J., Troyer, A. K., Levine, B., \& Moscovitch, M. (2008). Episodic, but not semantic, autobiographical memory is reduced in amnestic mild cognitive impairment. Neuropsychologia, 46(13), $3116-3123$

Neroni, M. A., Gamboz, N., De Vito, S., \& Brandimonte, M. A. (2016). Effects of self-generated versus experimenter-provided cues on the representation of future events. The Quarterly Journal of Experimental Psychology, 69(9), 1799-1811.

Piolino, P., Desgranges, B., Benali, K., \& Eustache, F. (2002). Episodic and semantic remote autobiographical memory in ageing. Memory, 10(4), 239-257.
Prull, M. W., Gabrieli, J. D. E., \& Bunge, S. A. (2000). Age-related changes in memory: A cognitive neuroscience perspective. In F. I. M. Salthouse \& C. T. A (Eds.), The handbook of aging and cognition (2nd ed., pp. 91-153). Mahwah: Erlbaum.

Race, E. A., Keane, M. M., \& Verfaellie, M. (2011). Medial temporal lobe damage causes deficits in episodic memory and episodic future thinking not attributable to deficits in narrative construction. Journal of Neuroscience, 31(28), 10262-10269.

Raudenbush, S. W., Bryk, A. S., Cheong, Y. F., Congdon, R. T., \& Du Toit, M. (2011). HLM 7 [Computer software]. Lincolnwood: Scientific Software International Inc.

Raz, N., Lindenberger, U., Rodrigue, K. M., Kennedy, K. M., Head, D., Williamson, A., . . Acker, J. D. (2005). Regional brain changes in aging healthy adults: General trends, individual differences and modifiers. Cerebral Cortex, 15(11), 1676-1689.

Rendell, P. G., Bailey, P. E., Henry, J. D., Phillips, L. H., Gaskin, S., \& Kliegel, M. (2012). Older adults have greater difficulty imagining future rather than atemporal experiences. Psychology and Aging, 27(4), 1089-1098.

Roberts, R. P., \& Addis, D. R. (2016). Future imagination and cognitive flexibility (Unpublished data). Auckland: School of Psychology, The University of Auckland.

Schacter, D. L., \& Addis, D. R. (2007). The cognitive neuroscience of constructive memory: Remembering the past and imagining the future. Philosophical Transactions of the Royal Society B, 362, 773786.

Schacter, D. L., Gaesser, B., \& Addis, D. R. (2013). Remembering the past and imagining the future in the elderly. Gerontology, 59(2), $143-151$.

Schacter, D. L., \& Madore, K. P. (2016). Remembering the past and imagining the future: Identifying and enhancing the contribution of episodic memory. Memory Studies, 9(3), 245-255.

Scherbaum, C. A., \& Ferreter, J. M. (2009). Estimating statistical power and required sample sizes for organizational research using multilevel modeling. Organizational Research Methods, 12(2), 347-367.

Snijders, T. A. B. (2005). Power and sample size in multilevel linear models. In B. S. Everitt \& D. Howell (Eds.), Encyclopedia of statistics in behavioral science. New York: Wiley. doi:10.1002/ 0470013192

Spaniol, J., Madden, D. J., \& Voss, A. (2006). A diffusion model analysis of adult age differences in episodic and semantic long-term memory retrieval. Journal of Experimental Psychology: Learning, Memory, and Cognition, 32(1), 101-117.

Squire, L. R. (1992). Memory and the hippocampus: A synthesis from findings with rats, monkeys, and humans. Psychological Review, 99(2), 195-231.

Squire, L. R., van der Horst, A. S., McDuff, S. G. R., Frascino, J. C., Hopkins, R. O., \& Mauldin, K. N. (2010). Role of the hippocampus in remembering the past and imagining the future. Proceedings of the National Academy of Sciences, 107(44), 19044-19048.

St. Jacques, P. L., \& Levine, B. (2007). Ageing and autobiographical memory for emotional and neutral events. Memory, 15(2), 129-144.

St. Jacques, P. L., Rubin, D. C., \& Cabeza, R. (2012). Age-related effects on the neural correlates of autobiographical memory retrieval. Neurobiology of Aging, 33(7), 1298-1310.

St-Laurent, M., Moscovitch, M., Levine, B., \& McAndrews, M. P. (2009). Determinants of autobiographical memory in patients with unilateral temporal lobe epilepsy or excisions. Neuropsychologia, 47(11), 2211-2221.

Svoboda, E., McKinnon, M. C., \& Levine, B. (2006). The functional neuroanatomy of autobiographical memory: A meta-analysis. Neuropsychologia, 44(12), 2189-2208. 
Tulving, E. (1972). Episodic and semantic memory. In E. Tulving \& W. Donaldson (Eds.), Organization of memory (pp. 381-402). New York: Academic Press.

Wang, T., Yue, T., \& Huang, X. T. (2016). Episodic and semantic memory contribute to familiar and novel episodic future thinking. Frontiers in Psychology, 7, 1746.

Wright, D. B. (1998). Modelling clustered data in autobiographical memory research: The multilevel approach. Applied Cognitive Psychology, 12(4), 339-357.
Zacks, R. T., \& Hasher, L. (1994). Directed ignoring: Inhibitory regulation of working memory. In D. Dagenbach \& T. H. Carr (Eds.), nhibitory processes in attention, memory, and language (pp. 241264). San Diego: Academic Press.

Zavagnin, M., De Beni, R., Borella, E., \& Carretti, B. (2016). Episodic future thinking: The role of working memory and inhibition on agerelated differences. Aging Clinical and Experimental Research, 28(1), 109-119. 